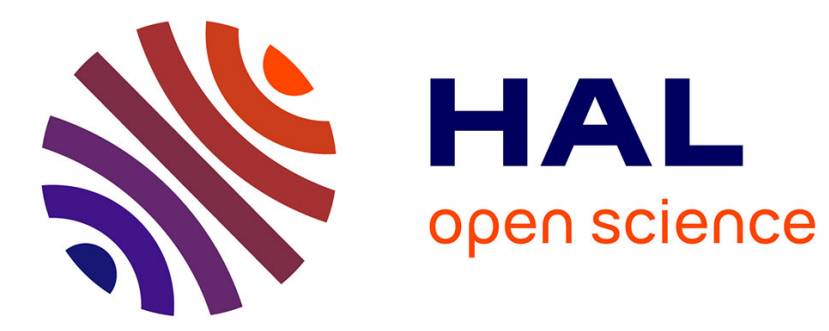

\title{
A capacitive micromachined ultrasonic transducer probe for assessment of cortical bone
}

\author{
Audren Boulmé, Sophie Ngo, Jean-Gabriel Minonzio, Mathieu Legros, \\ Maryline Talmant, Pascal Laugier, Dominique Certon
}

\section{- To cite this version:}

Audren Boulmé, Sophie Ngo, Jean-Gabriel Minonzio, Mathieu Legros, Maryline Talmant, et al.. A capacitive micromachined ultrasonic transducer probe for assessment of cortical bone. IEEE Transactions on Ultrasonics, Ferroelectrics and Frequency Control, 2014, 61 (4), pp.710-723. 10.1109/TUFFC.2014.2959 . hal-01302015

\section{HAL Id: hal-01302015 https://hal.sorbonne-universite.fr/hal-01302015}

Submitted on 13 Apr 2016

HAL is a multi-disciplinary open access archive for the deposit and dissemination of scientific research documents, whether they are published or not. The documents may come from teaching and research institutions in France or abroad, or from public or private research centers.
L'archive ouverte pluridisciplinaire HAL, est destinée au dépôt et à la diffusion de documents scientifiques de niveau recherche, publiés ou non, émanant des établissements d'enseignement et de recherche français ou étrangers, des laboratoires publics ou privés. 
Audren Boulmé( ${ }^{(1)}$, Sophie Ngo ${ }^{(2)}$, Jean-Gabriel Minonzio ${ }^{(3)}$, Mathieu Legros ${ }^{(4)}$, Maryline Talmant ${ }^{(3)}$, Pascal Laugier $^{(3)}$, Dominique Certon ${ }^{(1)}$

(1) François Rabelais University, GREMAN UMR-CNRS 7347, 10 Bd Tonnelle, Tours, France.

(2) STMicroelectronics, 10 rue Thalès de Milet, 37071 TOURS Cedex 2

(3) UPMC Univ Paris 06, LIP UMR-CNRS 7623, 15 rue de l'école de médecine, Paris, France. (4) Vermon SA, 180 Av. Général Renault, Tours, France.

\section{Abstract}

A wide range of ultrasound methods has been proposed to assess the mechanical strength of bone. Axial transmission technique, which consists of measuring guided elastic modes through the cortical shell of long bones such as the radius and the tibia, has recently emerged as one of the most promising approaches of all bone exploration methods. Determination of dispersion curves of guided waves is therefore of prime interest as they provide a large set of input data required to perform inverse process, and hence to evaluate bone properties (elastic and geometric). The cortical thickness of long bones ranges from approximately 1 to $7 \mathrm{~mm}$, resulting in wide inter-individual variability in the guided wave response. This variability can be overcome by using a single probe able to operate with a tunable central frequency typically, within the $100 \mathrm{kHz}-2 \mathrm{MHz}$ frequency range. However, there are certain limitations in the design of low frequency arrays using traditional PZT technology, and these limitations have triggered active research to find alternative solutions. Capacitive Micromachined Ultrasonic Transducers (cMUTs) present the potential to overcome these limitations and to improve axial transmission measurement significantly. The aim of the study presented here was to design and construct a new cMUT-based axial transmission probe and to validate the approach. We report all the steps followed to construct such a prototype, from the description of the fabrication of the cMUT (based on a surface micromachining process) through to probe packaging. The fabricated device was carefully characterized using both electrical and optical measurements in order to check the homogeneity of the device first from cMUT to cMUT and then from element to element. Finally, axial transmission measurements carried out with the prototype cMUT probe are shown and compared to results obtained with a counterpart PZT-based array.

Index Terms: cMUTs - Acoustic linear arrays - Cortical bone - Axial transmission - Lamb waves - Guided modes Osteoporosis - Surface micromachining 


\section{INTRODUCTION}

The most common methods used for assessment of skeletal status use X-ray-based techniques to determine bone mineral density (BMD) [1]. Although BMD is an important predictor of bone strength, its measurement alone fails to predict fracture risk accurately. Additional bone characteristics, including geometric microstructural and material properties, are required in order to assess the biomechanical competence of the bone more accurately. Ultrasound techniques are among the most promising modalities to fulfill this requirement [2]. Recent ex vivo experiments [3-7] carried out on long bones have shown that the cortical envelope of long bones behaves like an acoustic waveguide for frequencies between $100 \mathrm{kHz}$ and $2 \mathrm{MHz}$. Guided modes are sensitive to elastic and geometric properties of the waveguide. These results have encouraged new research to extend the concept of the axial transmission technique in order to exploit the waveguide character of cortical bone. Several axial transmission techniques have been described [8-14]. They are all based on the same measurement principle, consisting of using a set of emitters and receivers placed on the same side of the long bone, aligned with the bone axis. However, according to the operating conditions, different working frequency bandwidths and different signal processing techniques have been implemented, resulting in different waveforms being detected and subsequently processed: these include the first arriving signal (FAS) [15], an energetic late arrival signal [4] or a set of multiple guided waves $[3,7,14]$. Only FAS-based techniques have been clinically validated and they showed they were able to predict fracture risk [16]. However, this capacity is at best equivalent to that of X-ray densitometry, but not better. One major limitation of the FAS-based approach is that it measures only one parameter, i.e. FAS velocity, and it fails to yield a complete assessment of the various determinants of bone strength, such as cortical thickness, stiffness and porosity. Other approaches dedicated to a more comprehensive analysis of multiple recorded waveforms have recently been proposed $[6-7,14,17]$ and tested successfully on bone mimicking phantoms $[4,14]$ and on ex vivo bone specimens $[7,18]$. Briefly, cortical bone is considered as a waveguide and the guided mode spectrum is estimated [6-7, 14, 19] and a fit of the experimental spectrum to a model of the waveguide eventually yields estimates of the waveguide characteristics such as its thickness and stiffness coefficients $[4,17,20]$.

Our group has developed specific multi-emitter and multi-receiver ultrasonic transducers dedicated to axial transmission measurement [13] consisting of a 1-D linear array. In contrast to arrays used in pulse-echo imaging, the emitters and receivers are separated, so that each element of the array works either as an emitter or a receiver. The electronic driving circuits of the emitters and receivers are therefore simplified due to elimination of electronic protection circuits used in classical pulse-echo imaging. However, acoustic specifications and using 
conditions associated with axial transmission measurements require a probe with a wide bandwidth, able to cover the frequency bandwidth used for cortical bone testing, typically from $100 \mathrm{kHz}$ up to $2 \mathrm{MHz}$. In order to compensate for strong attenuation of the bone tissue, signals with high excitation amplitude are used to drive the probe and this generally leads to an increase in the temperature of the probe. The probe must thus withstand high temperature increases. Secondly, a wide angle directivity pattern is suitable in order to generate a large set of guided modes in the cortical bone. Finally, since all measurements are carried out in the near field of the probe, the electrical and acoustic cross-coupling phenomena must be treated with great care to avoid the presence of artifacts among the guided modes measured. In the study reported here we assumed that the characteristics offered by cMUT-based transducer technology (capacitive Micromachined Ultrasonic Transducers) should overcome some of the limitations encountered with PZT probes for our purposes. We present the fabrication and testing of an axial transmission probe based on cMUT technology and compare its performance with the results obtained with a PZT probe.

cMUTs are micro-electromechanical systems [21] introduced by P. Khuri-Yakub [22] and P. Eccardt [23] in 1996. They work like in-air microphones used in audio applications where mechanical vibration is produced by electrostatic forces instead of the piezoelectric effect used for standard technology. The topology of an acoustic cMUT-based antenna is defined by the pitch of the array, the kerf, the elevation and the number of emitters/receivers. Each acoustic radiator of an array is created by few thousand micro-membranes driven individually by electrostatic forces. The shape of each cMUT depends on the acoustic design: square, circular, polygonal or rectangular. The most advanced technological demonstrations with cMUT probes have been published in the field of classical pulse-echo imaging by O. Oralkan [24], R. O. Guldiken [25], G. Gurun [26], A. Savoïa [27], M. Legros [28] and A. Novell [29]. Why is cMUT technology suitable for axial transmission measurements? First, weak internal cross-talk exists in a cMUT probe, their directivity pattern is dependent only on the width of the emitter. In contrast, a standard PZT-based probe is a multi-layered structure in which guided modes can exist and create cross-talk which leads to narrowing of the directivity pattern. Secondly, the temperature increase is very low, as demonstrated by S. H. Wong et al. [30]. In a PZT probe the temperature increase is mainly caused by internal dielectric and mechanical losses while in the case of a cMUT probe there are no internal losses, since the main source of losses in a cMUT probe is the radiation of the acoustic pressure field. Finally, preliminary studies undertaken by Sénégond et al. [31] have demonstrated that a cMUT probe can operate at a central frequency fixed by its coupling with the fluid, but they can also generate efficient acoustic fields at very low frequencies, i.e. in a quasistatic regime. The reason is that, when a cMUT works at very low 
frequencies, it produces a very considerable displacement amplitude (close to the gap height value) which can somewhat compensate for the acoustic mismatching. However, despite strong non-linearities which characterize the low frequency behavior of cMUTs, we demonstrate here that such an operating regime can be used to enlarge the probe's bandwidth without any impact on the detection of guided modes in the plate under test.

This article comprises three parts. The first focuses on description of the probe design and its fabrication: from micromachining the cMUT up to the final packaging. A dedicated pre-amplification circuit was placed in the head probe to increase the signal to noise ratio. To help explain the design concept, we have added a reminder of the principle of axial transmission measurement. Simulations performed to establish sizes and topologies of the cMUT cells are also reported in the first section. The second section focuses on the characterization of the cMUT probe. It reports basic post-process measurements such as static deflection of the diaphragm performed on a non-packaged cMUT and acoustic pressure field measurements. The aim is to provide complete data for the probe from the unit cell up to the overall acoustic performance of the probe. Among all the output data provided, the homogeneity of the prototype from cell to cell and then from element to element is discussed. Finally, axial transmission tests carried out with the cMUT probe are reported in the last section. The acoustic phantom was a bone mimicking phantom. The results are discussed and compared with a PZT probe with the same topology.

\section{DESIGN AND FABRICATION OF THE CMUT PROBE FOR AXIAL TRANSMISSION MEASUREMENT}

\section{A. Principle of Axial Transmission Measurement: Topology of the Array}

Using a transducer in contact with the skin (Fig. 1), one acoustic pulse is emitted towards the cortical bone and then collected throughout its propagation using a set of transducers regularly spaced along the bone. If the emitter width is small enough at the skin/bone interface, according to classical refraction laws, the acoustic rays emitted in the skin are converted into guided modes in the cortical bone. The central frequency and bandwidth of the acoustic pulse select the type of guided modes propagated. In practical terms, the bandwidth to inspect bone tissue should be $100 \mathrm{kHz}-2 \mathrm{MHz}$. A set of RF signals is collected by the receivers to construct a data matrix that is dependent on time and distance, from which the dispersion curves of the guided modes can be determined [14]. Bossy et al. developed a specific biaxial transmission probe [13] to improve the signal to noise ratio and to compensate for the thickness of the soft tissue (mainly skin and fat). The designed probe of this study has similar topology (Fig. 2). It is divided into five zones: two emission arrays placed at the probe extremities, one reception array placed at the center of the probe and two dead zones for the propagation of waves. The specifications of 


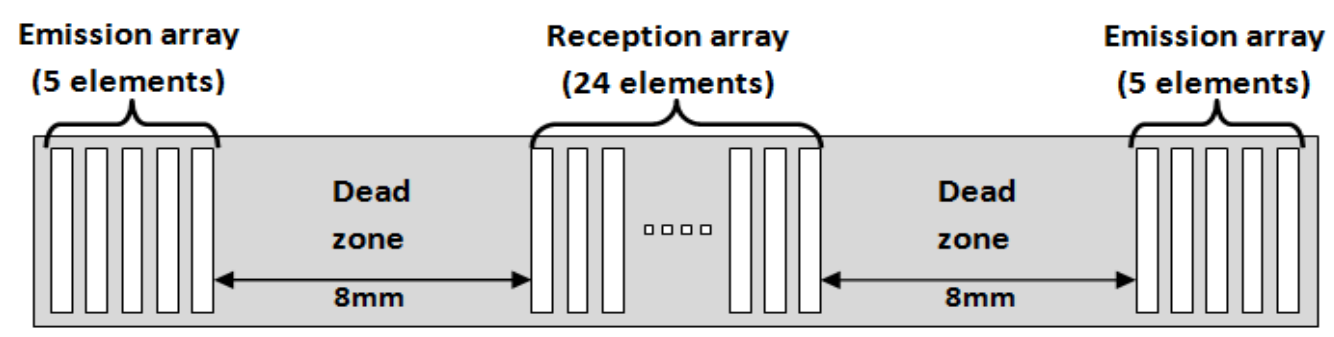

Fig. 2 Axial transmission probe topology

TABLE I

CMUT ARRAY DESIGN PARAMETERS

\begin{tabular}{ll}
\hline Parameter & Value \\
\hline Number of emitters per zone & 5 \\
Number of receivers & 24 \\
Dead zone width (azimuth), $\mathbf{m m}$ & 8 \\
Element width (azimuth), $\boldsymbol{\mu m}$ & 800 \\
Pitch of arrays (azimuth), $\boldsymbol{\mu m}$ & 890 \\
Element length (elevation), $\mathbf{m m}$ & 8 \\
\hline
\end{tabular}

\section{B. Design and Micromachining of cMUT Membranes}

A standard surface micromachining process [32] was used for the fabrication of the cMUTs. More details about the processes used in this work are given in [33], from which all the material properties used to design the cMUTs were obtained (see Table II). The membrane was made of low-stress silicon nitride $\left(\mathrm{SiN}_{\mathrm{x}}\right)$, and it was partially covered with an aluminum electrode. The metallization ratio was fixed at $50 \%$. The distances between columns and lines of cMUTs were fixed by the resolution of the photolithography apparatus (30 $\mu \mathrm{m}$ and $10 \mu \mathrm{m}$, respectively), difference being due to the presence of etching holes placed between columns. The thickness and the physical properties of each layer were fixed by the process constraints, (see Table II). The membrane size was first tuned to meet probe requirements: a central frequency within the $100 \mathrm{kHz}-2 \mathrm{MHz}$ range. However, to 
avoid the diaphragm sticking on the back of the cavity during the excavation of the sacrificial layer, the maximum size of the individual cMUTs was deliberately limited to $45 \times 45 \mu \mathrm{m}^{2}$. The simulations were performed with the model presented in [34] with 2D periodic boundary conditions. In view of the large number of cMUTs per $800 \mu \mathrm{m} \times 8 \mathrm{~mm}$ element, 2D periodic boundary conditions can be considered as good approximations to compute the response of the transducer. Fig. 3 shows the results of simulation for three sizes of square membranes $\left(25 \times 25 \mu \mathrm{m}^{2}, 35 \times 35 \mu \mathrm{m}^{2}\right.$ and $\left.45 \times 45 \mu \mathrm{m}^{2}\right)$. It can be seen that the $25 \times 25 \mu \mathrm{m}^{2} \mathrm{cMUT}$ was far from the targeted frequency band and could not be retained for the application. Although the central frequency for the two other sizes was higher than $2 \mathrm{MHz}$, part of the low frequency components of their spectra fell in the usable frequency band. They could therefore be used for bone exploration but operating at frequencies far lower than their central frequency (i.e. in quasistatic regime). Note that in previous studies [31], cMUT devices have shown one remarkable property in the quasistatic regime; they are able to produce very significant mechanical displacement (typically $100 \mathrm{~nm}$ ), and thus a significantly low frequency acoustic field, for tension voltage amplitudes lower than the collapse voltage value. A second criterion was used to fix the membrane size, i.e. the initial deflection of the membrane caused by the atmospheric pressure (Fig. 4). Fig. 4 sets out a design concern for the cMUT membrane. There is a clear trade-off between increasing the membrane size to reduce the central frequency and reducing the membrane size to avoid strong initial defection. Above $35 \mu \mathrm{m}$, the central frequency showed very small decreases and stagnated at values close to $4 \mathrm{MHz}$, while the deflection continued to increase strongly to reach $100 \mathrm{~nm}$. The membrane size was therefore fixed at $35 \times 35 \mu \mathrm{m}^{2}$. Finally, the gap height was tuned in order to obtain a moderate collapse voltage lower than $100 \mathrm{~V}$. This was fixed at $300 \mathrm{~nm}$, for a predicted collapse voltage of $87 \mathrm{~V}$.

TABLE II

MECHANICAL PROPERTIES OF CMUT MEMBRANE MATERIAL

\begin{tabular}{lcc}
\hline Layer & Membrane $\left(\mathrm{SiN}_{\mathbf{x}}\right)$ & Electrode $(\mathrm{Al})$ \\
\hline Thickness $(\mathbf{n m})$ & 550 & 450 \\
Young's modulus $(\mathbf{G P a})$ & 240 & 68 \\
Poisson coefficient & 0.25 & 0.35 \\
Density $\left(\mathbf{k g} / \mathbf{m}^{\mathbf{3}}\right)$ & 3300 & 2700 \\
Relative permittivity & 7.5 & \\
\hline
\end{tabular}




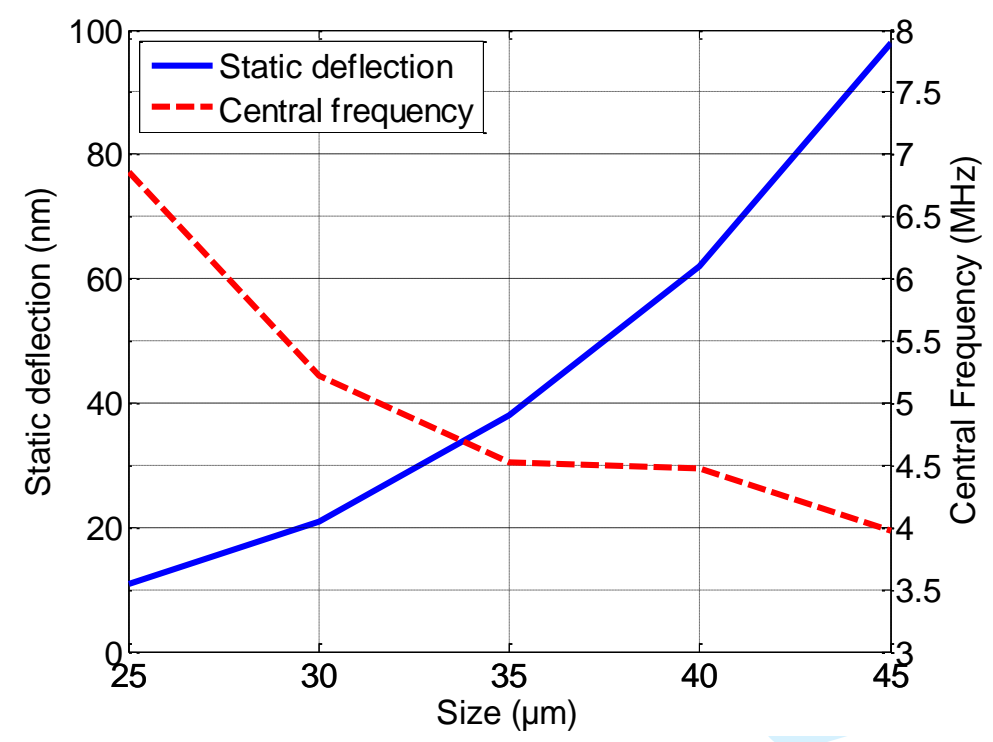

Fig. 4 Central frequency and static deflection in relation to membrane width

\section{Packaging}

A specific packaging procedure was developed for this cMUT probe. In view of the final application, the classical integration process of the cMUT chip was reconsidered. The main steps of this packaging procedure are summarized diagrammatically in Fig. 5. First, a printed circuit board (PCB) adapted to the geometry of the axial transmission probe was fabricated. On this PCB, three different ground planes were designed in order to prevent electrical coupling between emitters and receivers. Each zone was therefore electrically independent. A $500 \mu \mathrm{m}$ 
thick glass-ceramic layer was stuck on the PCB (Fig. 5 (a)) in order to protect the PCB during the dicing step (Fig. 5 (c)) and absorb the thickness mode resonance of the substrate. The next step (Fig. 5 (b)) was the bonding of the cMUT chip to the glass-ceramic layer after verifying the alignment of the PCB pads with those of the cMUT chips. The cMUT chip was then diced in the middle of each dead zone (Fig. 5 (c)) in order to reinforce reduction of acoustic and electrical cross-talk through the substrate. Interconnection between the cMUT chip and the PCB was established with a manual wedge bonder (Fig. 5 (d)). Wire bonding was performed using $25 \mu \mathrm{m}$ diameter gold wires. The wire bonds were then covered with an epoxy resin to protect them from ageing and the risk of mechanical damage (Fig. 5 (e)). In addition, this kind of epoxy resin ensures electrical insulation and avoids local temperature increases. Finally (Fig. 5 (f)), an acoustic lens made of Room Temperature Vulcanization (RTV) silicone was placed on the device. The thickness of the lens was fixed at $300 \mu \mathrm{m}$, as the best trade-off between a high value to ensure safety and a low value to minimize interactions between the guided modes of the silicone layer and those of the plate being tested. Photographs of the packaged cMUT probe are provided in Fig. 6.

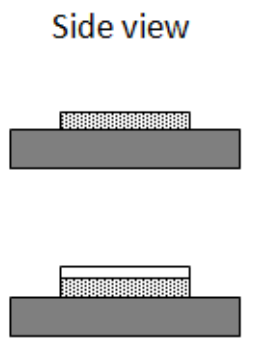

Top view

(a)

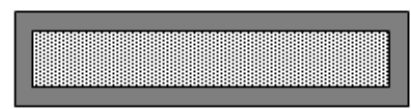

(b)
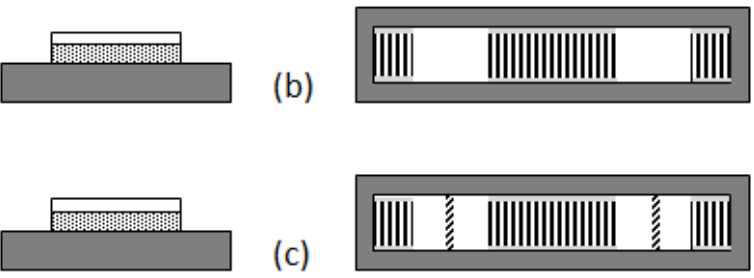

(c)
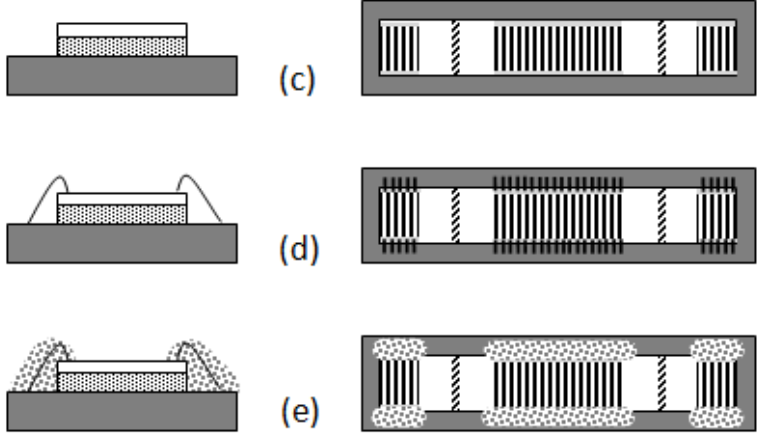

(e)
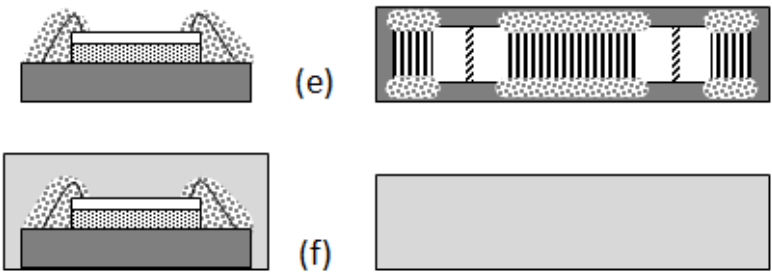

(f)

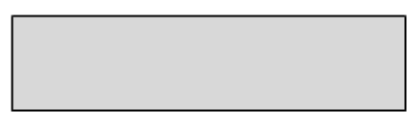

\section{PCB $\quad$ Alumina $\square$ cMUT chips $\quad$ Epoxy resin $\square$ silicone rubber}

Fig. 5 Main steps of the packaging procedure for the cMUT probe for cortical bone assessment 


\section{Characterization OF CMUT PROBE}

To check the functionality and the homogeneity of the cMUT probe from cell to cell and from element to element, a set of basic post-process characterizations was first performed as follows: visual inspection with an optical microscope, static deflection measurement with DC biasing voltage and electrical measurements. Additional characterizations were done in order to assess electro-acoustic performances of the cMUT probe prototype, with first pressure field measurements and then, with pitch-catch measurements carried out through a thick solid material.

\section{A. Post-process Characterizations}

To check the cell to cell homogeneity, the static deflection with a DC biasing voltage of 480 cMUTs belonging to the same element was measured with a Digital Holographic Microscope (DHM). The method was previously described in [36]. From the hysteretic cycle of each sample, collapse and snapback voltages were 
measurable without any ambiguity. The group of cMUTs was distributed around one mean value of $88 \mathrm{~V}$ and 40 $\mathrm{V}$ respectively, with a variance of $2 \%$.

To check the element to element reproducibility, electrical impedance measurements were performed in air with DC biasing voltage. For each element, the maximum value of the electromechanical coupling coefficient measured was 0.7 , at a biasing voltage close to the collapse voltage. Three parameters extracted from the electrical impedance curves were used for comparison, i.e. the low frequency capacitance, the resonance frequency in air and the collapse voltage. The mean values obtained for these three parameters and their corresponding standard deviation are given in Table III. The low frequency capacitance and the resonance frequency in air were obtained for a bias voltage of $66 \mathrm{~V}$. Good homogeneity was observed, despite the large cMUT array $(44 \times 8 \mathrm{~mm})$. The standard deviation did not exceed $5.5 \%$ for the three parameters The mean value of the collapse voltage was $90 \mathrm{~V}$, and was thus in real agreement with the mechanical determination. This value was therefore retained for each element to fix operating conditions of later experiments.

TABLE III

CMUT PARAMETERS OBTAINED FROM OF ELECTRICAL IMPEDANCE

\begin{tabular}{ccc}
\hline & Mean value & Standard deviation \\
\hline Collapse voltage $(\mathbf{V})$ & 90.47 & $4.78(5.3 \%)$ \\
Resonance frequency $(\mathbf{M H z})$ & 5.67 & $0.08(1.4 \%)$ \\
Low frequency capacitance $(\mathbf{p F})$ & 53.2 & $2.23(4.2 \%)$ \\
\hline
\end{tabular}

\section{B. Pressure Measurements}

All the acoustic measurements were performed with the same prototype probe. The electro-acoustic response and the directivity pattern of one element were measured in water using a laser interferometer with the technique described in [37]. This consisted of exciting a single emitter and then collecting the displacement on the front face of the probe. The scan of the pitch is generally fixed at one tenth of the acoustic wavelength. The data set is then used to compute the output pressure field using the Rayleigh integral. This method was chosen because hydrophones are rarely calibrated for large bandwidth operations, meaning that for this study several hydrophones should have been used to measure the output pressure from $500 \mathrm{kHz}$ to $10 \mathrm{MHz}$. The laser interferometer used here (TEMPO-200, Bossa Nova, Culver City, CA, USA) provided calibrated output displacements from $20 \mathrm{kHz}$ up to $100 \mathrm{MHz}$, and therefore pressure measurements were also calibrated. Obviously the acousto-optic interactions must be compensated for and the technique described in [37] was used here. The electronic driver was an arbitrary waveform generator (AFG3102, Tektronix, Beaverton, OR, USA) 
controlled by computer, the output signal of which was amplified with a linear power amplifier (150A100B, Amplifier Research, Souderton, PA, USA). The bias voltage source was a standard continuous supply (PPS1007, Motech, New Taipei City, Taiwan). The same apparatus was used for all the experiments described below.

In the first step, a wideband pulse was used to compare the measured central frequency and bandwidth with theoretical values and to determine the directivity pattern. The excitation signal was a half period of sinus function the $-6 \mathrm{~dB}$ fractional bandwidth of which extended to $20 \mathrm{MHz}$. The operating conditions in terms of bias voltage and excitation amplitude were fixed after rapid scanning of the displacement amplitudes when the bias voltage varied. In order to prevent the collapse event, the peak voltage allowed on the emitters was set at the collapse voltage $(90 \mathrm{~V})$. Thus, for each biasing voltage $\left(V_{0}\right)$, the pulse amplitude $\left(v_{a c}\right)$ was adjusted in order to obtain the peak voltage $\left(V_{0}+v_{a c}\right)$ equaling the collapse voltage $(90 \mathrm{~V})$. These experimental conditions were chosen to limit the risk of charging effects when the diaphragm touched the bottom electrode, although no charging effects were observed during the characterization step. The pair of values producing the highest displacement was $+20 \mathrm{~V}$ for pulse amplitude and $+70 \mathrm{~V}$ for polarization voltage. The pulse and the bias voltage had the same sign. These driving conditions were retained for later experiments. The impulse response of one element tested at a distance of $1 \mathrm{~mm}$ from the emitter and the corresponding spectrum are reported in Fig. 7. The central frequency and $-6 \mathrm{~dB}$ fractional bandwidth were $7.4 \mathrm{MHz}$ and $115 \%$, respectively. The theoretical spectrum is accurately superimposed on the experimental curve in Fig. 7 (b). This result confirmed that the measured performance matched very well with the initial targeted specifications. The peak-to-peak output pressure amplitude $(120 \mathrm{kPa})$ was somewhat lower than values commonly published in the literature. This result was expected, since it was explained by the active surface ratio. For this first prototype, the inter-cell distances were intentionally designed with high values to avoid any risk of alignment errors. However, this was not a key parameter for the demonstration prototype since the use of a photolithography machine with greater precision can easily improve the pressure amplitude. Fig. 8 shows the directivity pattern of the element obtained with the same excitation, namely the variations in the pressure spectrum against the radiation angle. Within the usable frequency range for bone characterization (i.e. $100 \mathrm{kHz}-2 \mathrm{MHz}$ ) it can be seen that the angular spectrum was wide enough (here $50^{\circ}$ ) to generate a large number of guided modes in cortical bone. In contrast to PZT probe, the directivity pattern of this prototype was very close to that of an ideal rectangular source, so that no parasitic structure modes disturbed the acoustic field at very low frequencies, as reported in [38]. 
(a)

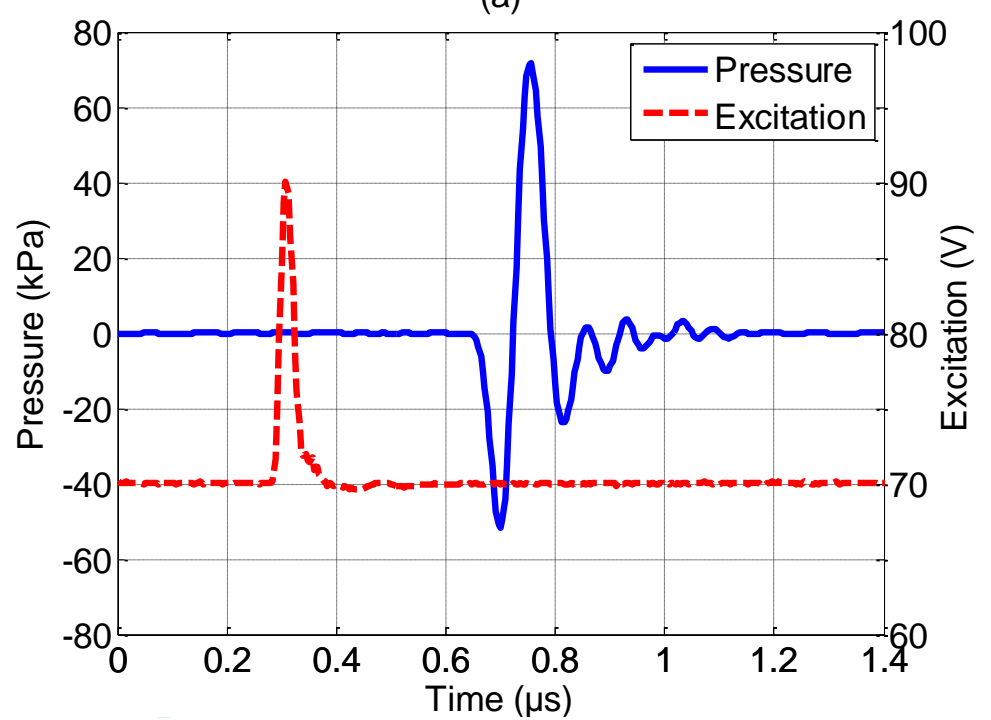

(b)

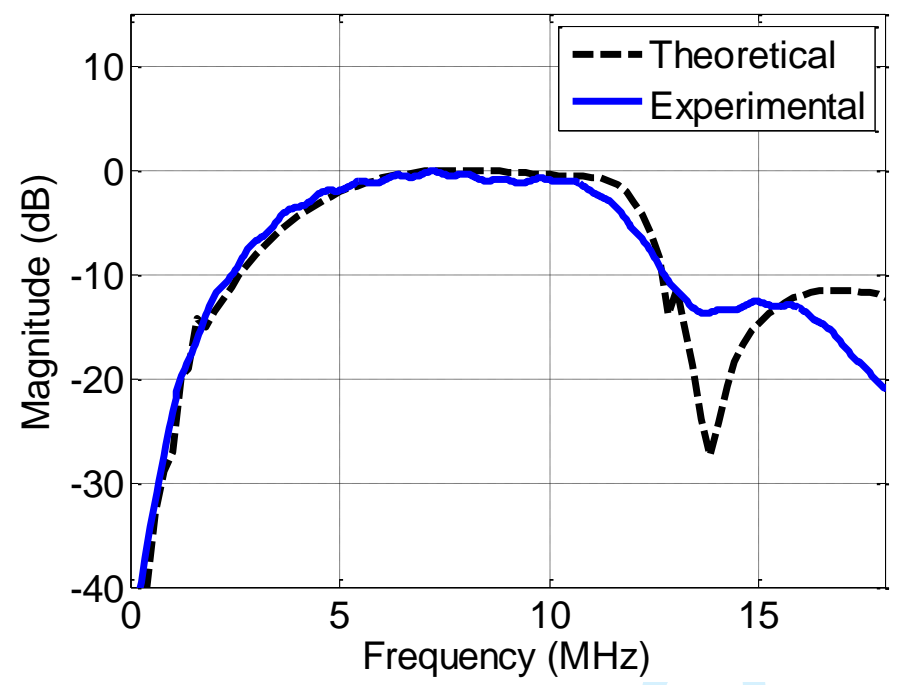

Fig. 7 (a) Excitation signal of one element (red dashed line) and the corresponding impulse response (blue continuous line) and spectrum (b). The blue continuous line represents the experimental spectrum and the black dashed line the theoretical spectrum. 
3

4

5

6

7

8

9

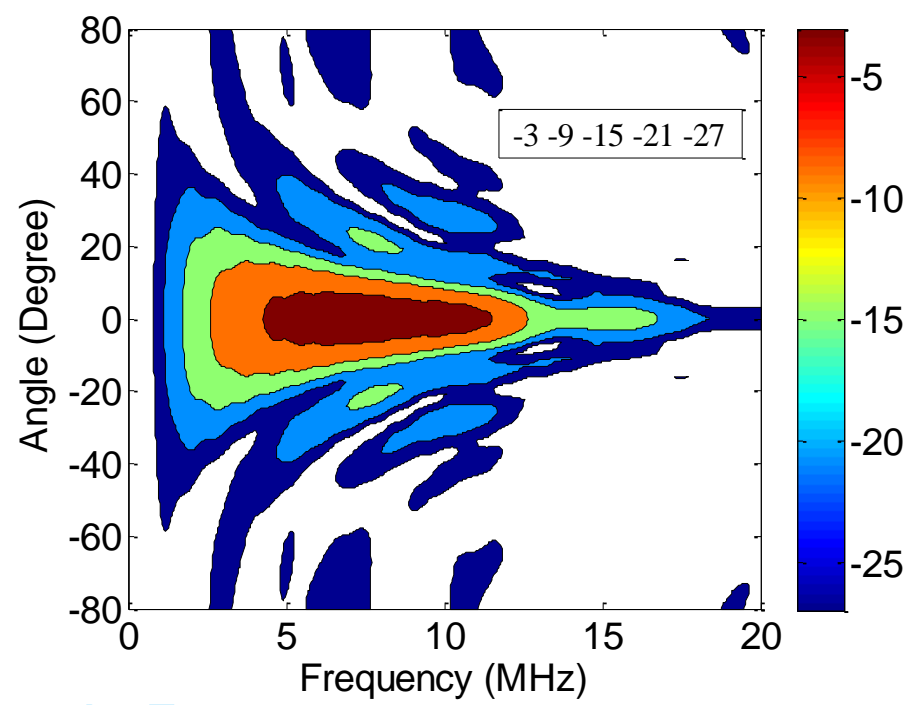

Fig. 8 2D directivity pattern of one element

\section{Pitch Catch Measurements}

In order to assess the performance of the cMUT probe, pitch-catch measurements were carried out through a thick solid material. The same DC power supply was used for biasing both emitters and receivers. To mimic real operating conditions more closely, the thick material chosen had to be strongly attenuating and here it was a block made of $20 \mathrm{~mm}$ thick silicone polymer. The cMUT probe was in contact with the silicone block and the transmitted pulse between one emitter and one receiver was measured. The excitation signal applied to the emitter was an apodized toneburst of 4 sinusoidal cycles. A small narrowband signal was chosen here to verify that the cMUT vibration followed the same frequency as the excitation forces, even in quasistatic regime. The central excitation frequency was tuned to cover the usable frequency bandwidth of the final application, namely characterization of cortical bone. Three frequencies were selected: $500 \mathrm{kHz}, 1 \mathrm{MHz}$ and $1.5 \mathrm{MHz}$. The operating conditions were the same as for the pressure measurements, i.e. a bias voltage of $+70 \mathrm{~V}$ and a peak amplitude of $20 \mathrm{~V}$. The time and frequency responses obtained for each excitation are reported in Fig. 9. At $500 \mathrm{kHz}$ (Fig. 9 (a) and (d)), although the emitter was working at very low frequencies, the received signal was well centered at the excitation frequency and the amplitude was significant. The amplitude distortion observed was expected since it originated from the nonlinear behavior of the cMUT. The distortion phenomenon created two nonlinear spectral components at $1 \mathrm{MHz}$ and $1.5 \mathrm{MHz}$, with relative amplitudes of $-9 \mathrm{~dB}$ and $-12 \mathrm{~dB}$, respectively. As will be demonstrated in the next section, this phenomenon did not hamper the axial transmission technique. On the contrary, it contributed to energy production in a larger frequency bandwidth and therefore to excitation of more guided modes in the cortical bone. With excitation centered at $1 \mathrm{MHz}$ (Fig. 9 (b) and (e)) and $1.5 \mathrm{MHz}$ (Fig. 9 
(c) and (f)), the spectra of received signals were well centered at $1 \mathrm{MHz}$ and $1.5 \mathrm{MHz}$, respectively. Since cMUT behavior is further from the quasistatic regime, the third harmonic components had disappeared and the amplitude of the second harmonic fell to $-20 \mathrm{~dB}$ at $1 \mathrm{MHz}$ and $-28 \mathrm{~dB}$ at $1.5 \mathrm{MHz}$.

(a)

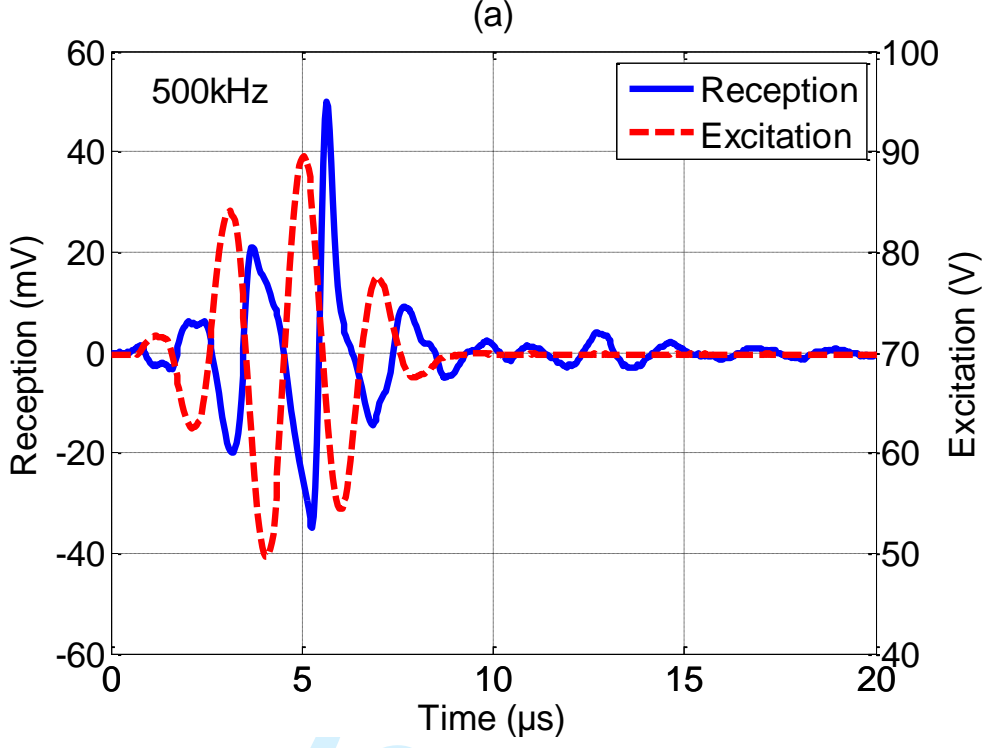

(b)

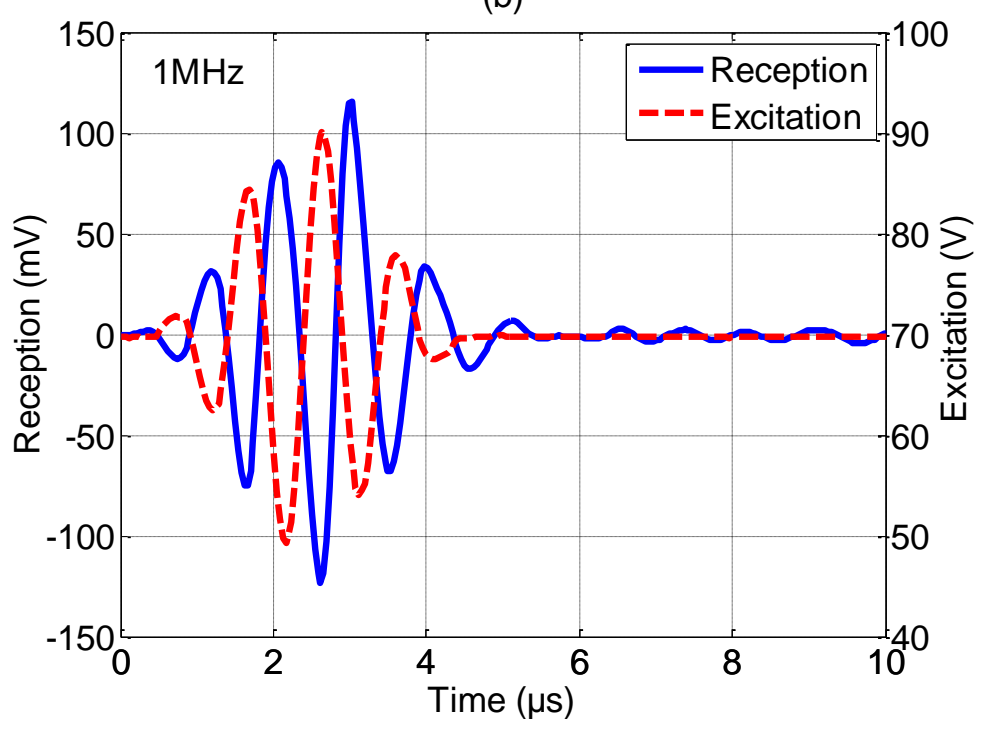

50

51

52 
(c)

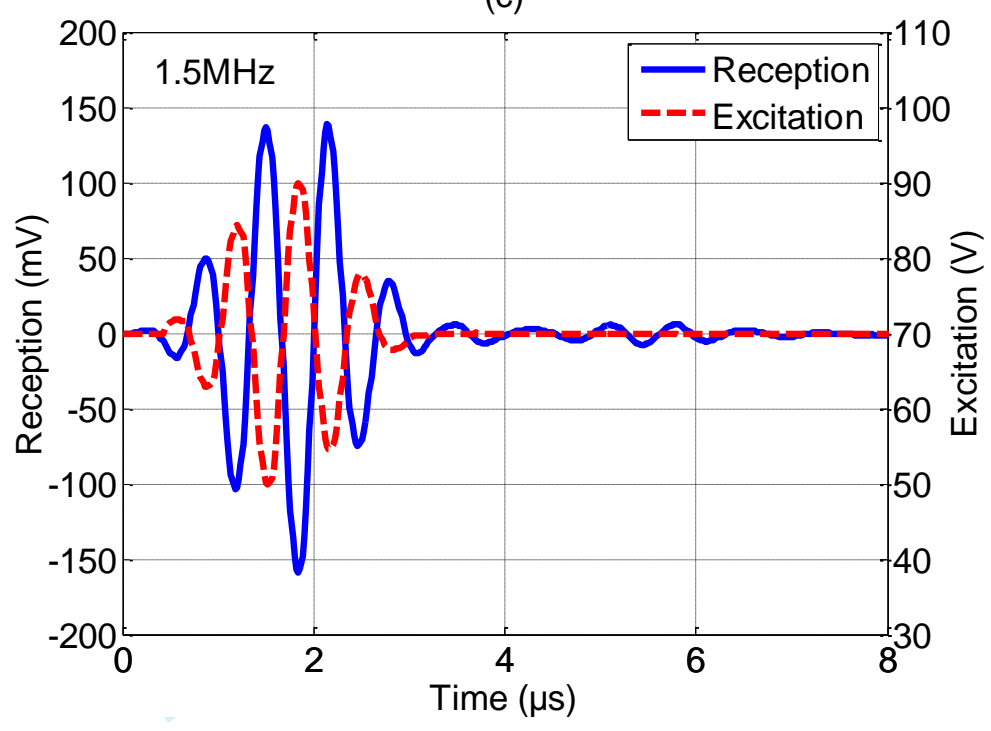

(d)

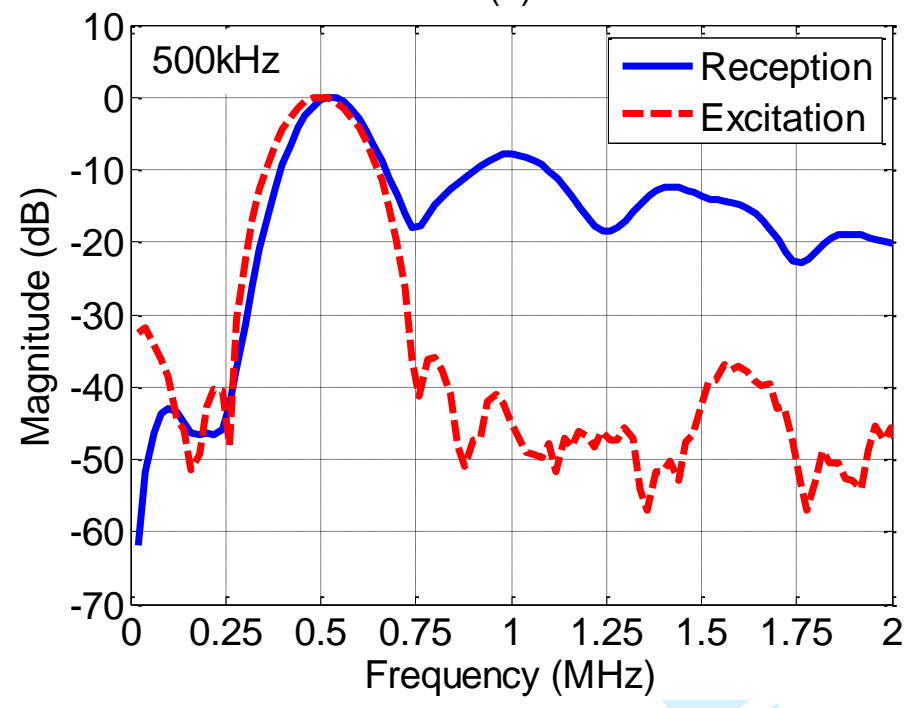

(e)

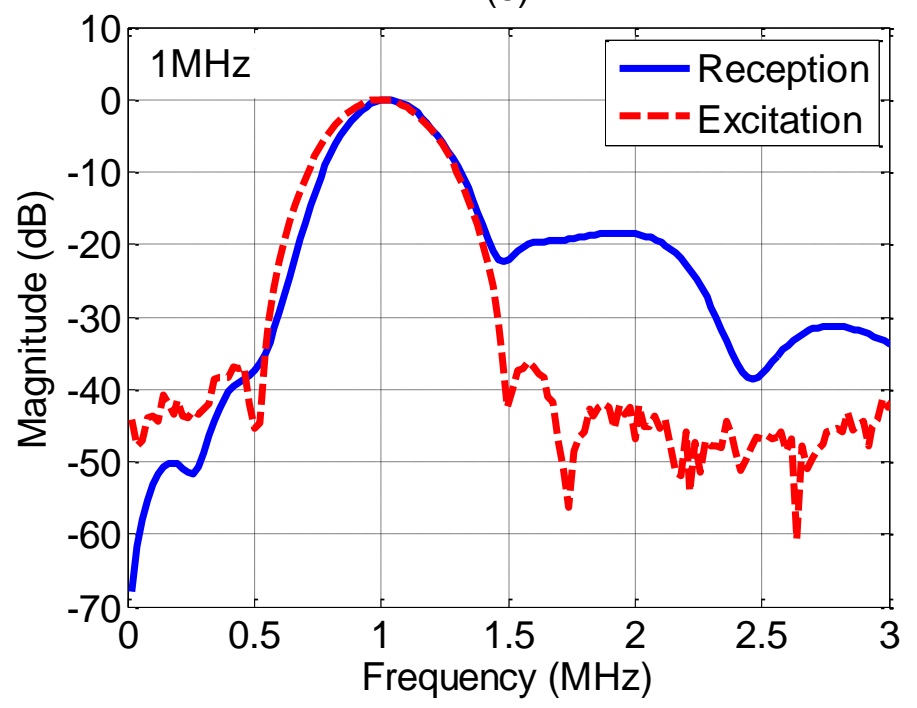


(f)

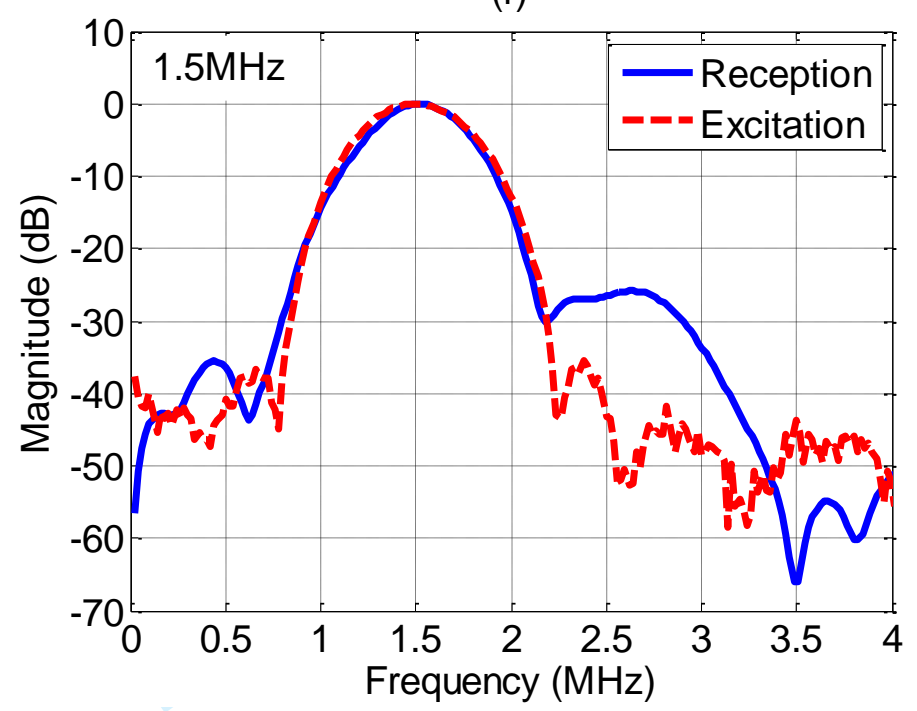

Fig. 9 Pitch-catch measurements performed with preamplifying circuits for a toneburst centered at $500 \mathrm{kHz}$ ((a) and $(d)), 1 \mathrm{MHz}((b)$ and $(e))$ and $1.5 \mathrm{MHz}((c)$ and $(f))$. The emission signal is superimposed for each excitation frequency.

\section{AXIAL TRANSMISSION TESTS}

\section{A. Axial Transmission Measurements}

The axial transmission tests were performed on a bone-mimicking plate. This plate, already described and tested in $[14,39]$ was made of oriented glass fibers mixed with epoxy resin. It belongs to the transversely isotropic material class, with elastic properties close to those of real bones. The probe packaging was the same as for pitch-catch measurements, the first axial transmission measurements were therefore carried out with the same conventional laboratory instruments as those described in sections III-B and III-C. Two electronically driven multiplexers were used, one for the group of emitters and one for the group of receivers. The experimental setup is described in Fig. 10. The axial transmission matrix was then constructed almost instantly and contained all the temporal signals $r_{i j}(t)$, with $i$ and $j$ the transmitter and receiver indices, respectively. First, the cMUT probe was placed on the bone mimicking plate. Probe-plate coupling was achieved with classical acoustic gel. For all the axial transmission tests, the excitation voltage was a wideband signal, namely a single period of sinus-shaped function. The central frequency was changed in order to extend the observation of guided modes and not be restricted by the frequency band defined by the application. Thus, two different frequencies were tested: $500 \mathrm{kHz}$ and 1.5 MHz. The bias voltage and peak amplitude of excitation were retained ( $+70 \mathrm{~V}$ and $+20 \mathrm{~V}$, respectively).

An example of seismic representation of data collected on all the receivers for one of the emitters is given in Fig. 11. For both excitations, the shape of the RF signals clearly indicates the presence of dispersive waves 


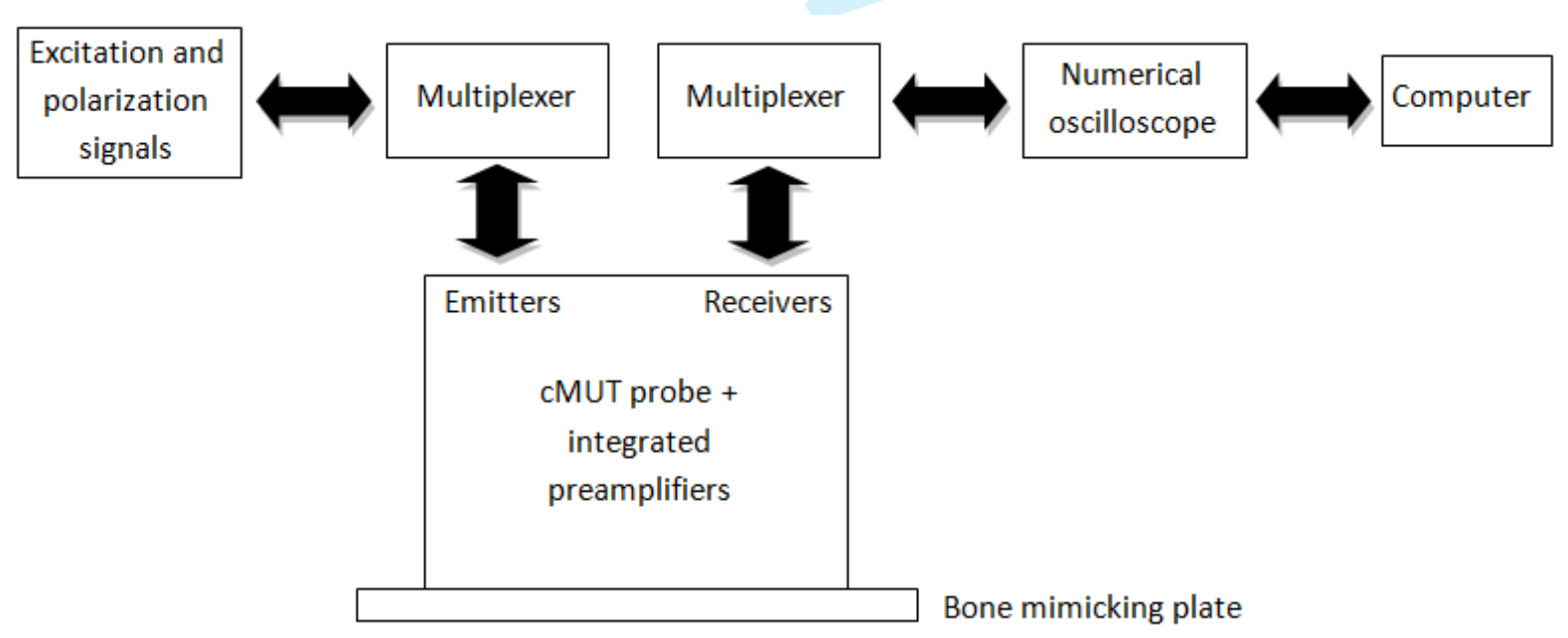

Fig. 10 Experimental setup of axial transmission measurements rapidly with distance, and data collected at $1.5 \mathrm{MHz}$ were much lower in amplitude than at $500 \mathrm{kHz}$. Nevertheless, the signal-to-noise ratio of the received signals was high enough to apply the singular value decomposition method [14] successfully to the data matrix measured. This method transforms the time $t /$ space $x$ diagram (Fig. 11) into a time frequency $f /$ spatial frequency $k$ diagram (Fig. 12), known as the Norm function. Fig. 12 shows that the symmetrical and anti-symmetrical guided modes in the plate were clearly identified in the $100 \mathrm{kHz}-2 \mathrm{MHz}$ frequency range for both excitations. The quality of the two images in terms of noise follows the center frequency of the excitation. Dispersion curves clearly stand out from the noise from $100 \mathrm{kHz}$ to 1.3 $\mathrm{MHz}$ for the lowest frequency and then from $0.7 \mathrm{MHz}$ to $2.2 \mathrm{MHz}$ for the highest frequency. Dispersion curves can even be distinguished up to $3 \mathrm{MHz}$ despite ultrasound attenuation. However, the most challenging aim was the measurement of guided modes at low frequencies. The $500 \mathrm{kHz}$ image clearly demonstrates that the cMUT technology was able to reach this objective operating in quasistatic regime. The mode, annotated $L$ on the two figures (Fig. 12 (a) and (b)), could be interpreted as a wave propagating mainly in the silicone layer as this mode was weakly dispersive with frequency and its phase velocity tended towards the limit of $990 \mathrm{~m} . \mathrm{s}^{-1}$, close to the longitudinal speed of sound in the silicone material. It corresponds to the Stoneley-Scholte interface wave already described by previous literature [40-41]. It can easily be suppressed since it appears at very low frequencies and it does not interact with the usable guided mode of the plate. 
(a)

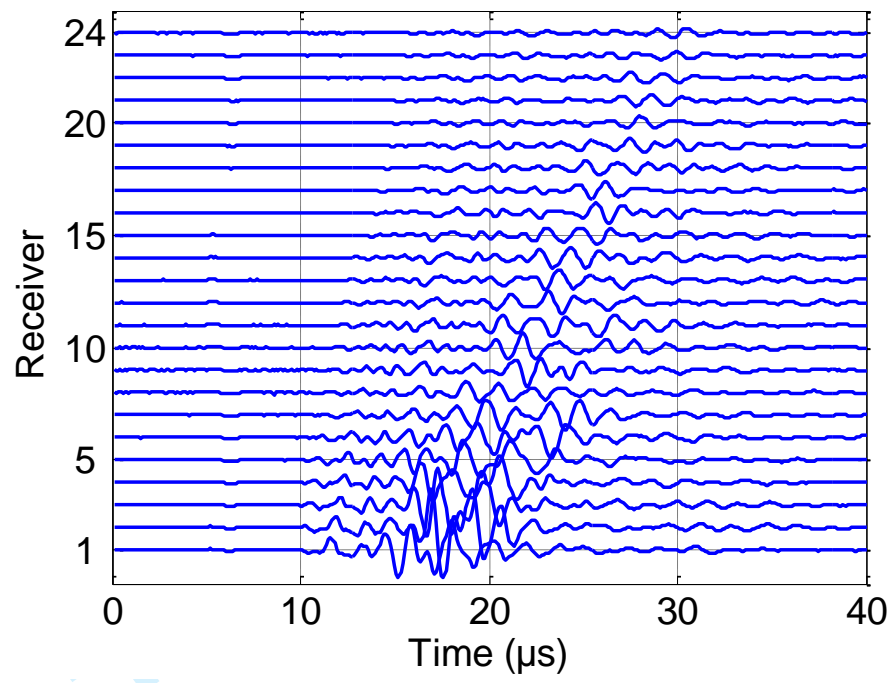

(b)

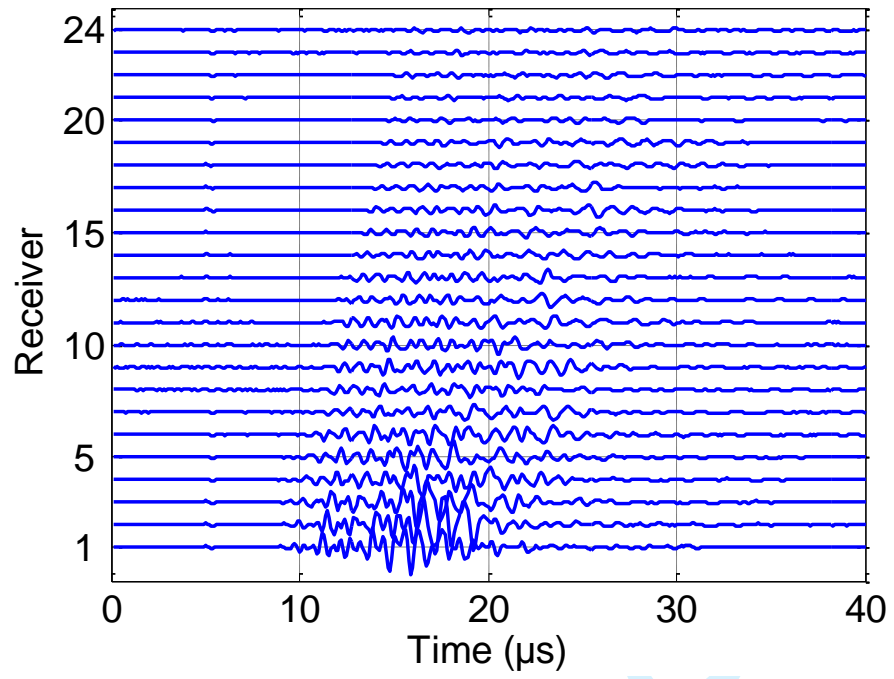

Fig. 11 Seismic representation of the 24 RF data received when one emitter was used for excitation centered at $500 \mathrm{kHz}($ a) and at $1.5 \mathrm{MHz}(\mathrm{b})$. 


\section{B. Comparison with Standard PZT Probe}

The dispersion curves obtained with a standard PZT probe and with cMUT probe were compared. The PZT probe used for these experiments had the same topology as the cMUT probe, i.e. array pitch and elevation were identical. The main difference was in the acoustic design since the PZT material was chosen to have a central frequency of $1 \mathrm{MHz}$. Passive acoustic layers and backing were added to the PZT material in order to obtain as wide a bandwidth as possible. The PZT probe was scanned with a laser interferometer and tested with the same operating conditions as described in section III-B. The effectiveness of the probe is reported in Fig. 13 (impulse response) and Fig. 14 (2D directivity pattern). As expected, the PZT probe response was mainly centered at 1 MHz, with a $-6 \mathrm{~dB}$ fractional bandwidth of $90 \%$. The peak-to-peak amplitude of the output pressure was 140 $\mathrm{kPa}$, and the 2D directivity pattern was the typical shape of PZT-based medical imaging probes, as described in 
reference [38]. Comparison with the cMUT probe directivity pattern is fairly difficult since the natural way these two transduction technology types couple with a fluid medium is fundamentally different. Three small branches could be distinguished at the $-3 \mathrm{~dB}$ contour level (Fig. 14). These corresponded to the existence of three coupled guided modes propagating inside the probe [38]. At angle $=0^{\circ}$, these modes were the combination of three thickness resonances in each layer of the sandwich made with the PZT plate coupled to the matching layers. The contour levels at -9 and $-15 \mathrm{~dB}$ showed the same behavior. However, at -21 and $-27 \mathrm{~dB}$, small additional branches appeared at an angle of $50^{\circ}$ and $0.5 \mathrm{MHz}$ which corresponded to other low frequency guided modes in the PZT probe. In summary, the usable energy radiated by the PZT probe was mainly contained in the area defined by the $-15 \mathrm{~dB}$ contour level. The maximum directivity was obtained at $750 \mathrm{kHz}$ at an angle of $50^{\circ}$, while the directivity at $-15 \mathrm{~dB}$ fell to $20^{\circ}$ at a frequency of $1.5 \mathrm{MHz}$. Note that $20^{\circ}$ was obtained with the cMUT probe only at $5 \mathrm{MHz}$.

(a)

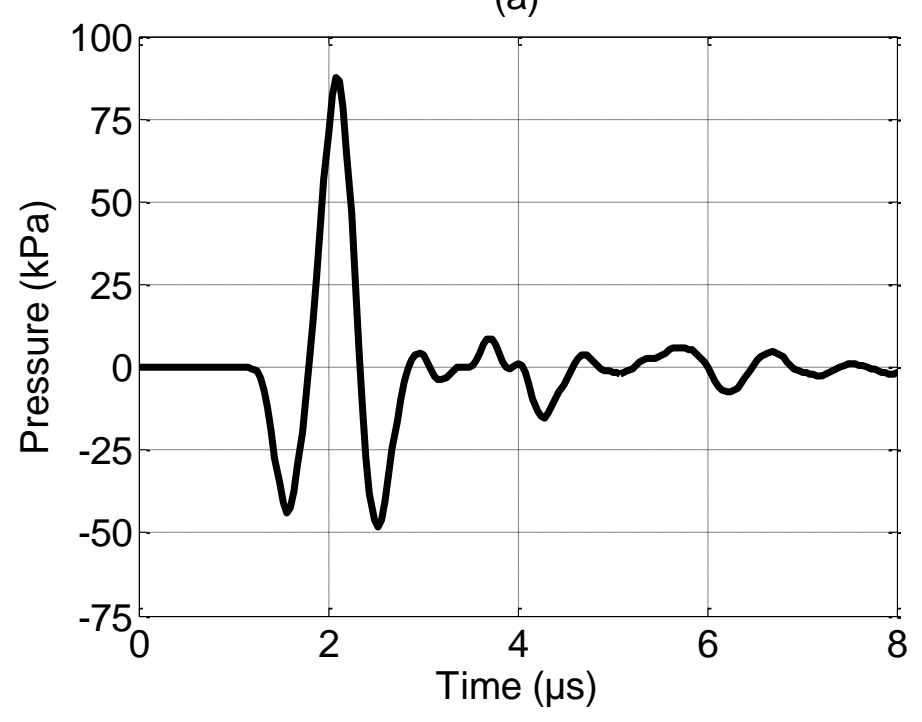




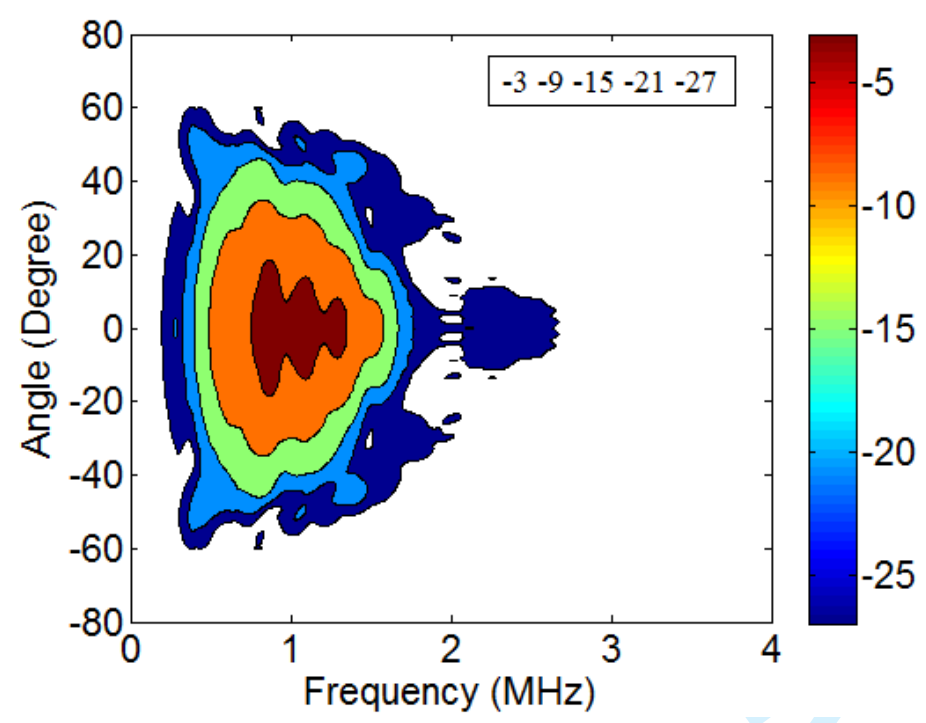

Fig. 14 2D directivity pattern of one element of the standard PZT probe

The two sets of experimental dispersion curves extracted from the maxima of the two Norm functions measured for each technology type are drawn in Fig. 15 and compared with the theoretical curves obtained for the free plate model described in [14]. In this figure, the previously described L mode was removed for both probes. The experimental guided modes were in overall good agreement with the free plate modes with only few deviations. Experimental data close to $\mathrm{A}_{0}$ and $\mathrm{S}_{0}$ branches on the free plate deviated from these branches at the highest $\mathrm{k}$ values $\left(\mathrm{k}>3.5 \mathrm{rad} . \mathrm{mm}^{-1}\right)$. Similarly, the experimental results close to the $\mathrm{S}_{2}$ branch of the free plate 
were split into two trajectories at around $\mathrm{f}=1 \mathrm{MHz}$ and $\mathrm{k}=1 \mathrm{rad} \cdot \mathrm{mm}^{-1}$. Detailed analysis of the experimental data (not reported here) suggested that Lamb wave measurements performed with a linear array followed a fluid/solid bilayer model more effectively than a free plate model, whatever the technology used (cMUT or PZT). It is believed that the major cause was the presence of the intermediate layer made of silicone which acted as a waveguide and coupled genuine Lamb waves in the sample. As a result of the coupling between the two elementary waveguides, dispersion curves of the bilayer deviated from the dispersion curves of the free elastic plate alone [41-42]. Nevertheless, as this refined model was not within the scope of the study, the Lamb wave dispersion curves of the free plate were used as reference and showed overall satisfactory agreement with experimental data, as shown on Fig. 15.

Deviation from the free plate modes can also be discussed in terms of resolution linked to the ability of both probes to detect two close modes. As described in [14], resolution increases with reception length and it thus was the same for both probes (i.e. about 0.3 rad. $\mathrm{mm}^{-1}$ ). If two modes are closer than the resolution, only one intermediate mode placed between the two actual modes can be detected. This phenomenon was observed for modes $S_{1}, S_{2}$ and $A_{2}$ for frequencies within the $1-1.25 \mathrm{MHz}$ band and wave-vectors between 1.75 and 2.75 rad. $\mathrm{mm}^{-1}$.

Overall, as can be clearly seen in Fig.15, the cMUT probe allowed the detection of a larger number of guided modes due to the high directivity and wide frequency bandwidth of cMUTs. Above $\mathrm{f}=1.2 \mathrm{MHz}$ and above $\mathrm{k}=$ $3.5 \mathrm{rad} . \mathrm{mm}^{-1}$, the $\mathrm{A}_{1}$ mode was detected only with the cMUT probe due to difference in directivity. On the other hand, above $2 \mathrm{MHz}$, guided modes were detected only with the cMUT probe, due to the wider frequency bandwidth. This gives this technology an undeniable advantage for axial transmission applications and, more generally for non-destructive evaluation of material, since measurements can be carried out with a single probe in a very wide frequency band, i.e. from a few hundred $\mathrm{kHz}$ to a few $\mathrm{MHz}$.

Finally, the ability to tune the central frequency of the ultrasonic field is a considerable advantage for the measurement of modes guided by cortical thickness. Bone exhibits wide variability in inter-individual cortical thickness (typically 1 to $4 \mathrm{~mm}$ for the radius), thus corresponding to highly different waveguide behaviors for a fixed frequency bandwidth, i.e. from low (only two modes $\mathrm{A}_{0}$ and $\mathrm{S}_{0}$ ) to high mode density as the frequencythickness product increases. In practice, for a plate at a given thickness, the optimal number of modes is a tradeoff between two extreme cases: if the number of modes is too low, not enough input data may be measured to perform inverse process, and if the number of modes is too high, inverse process may be unresolved. Tuning the central frequency with the same probe, as offered by cMUTs, thus ensures maintaining an appropriate mode 


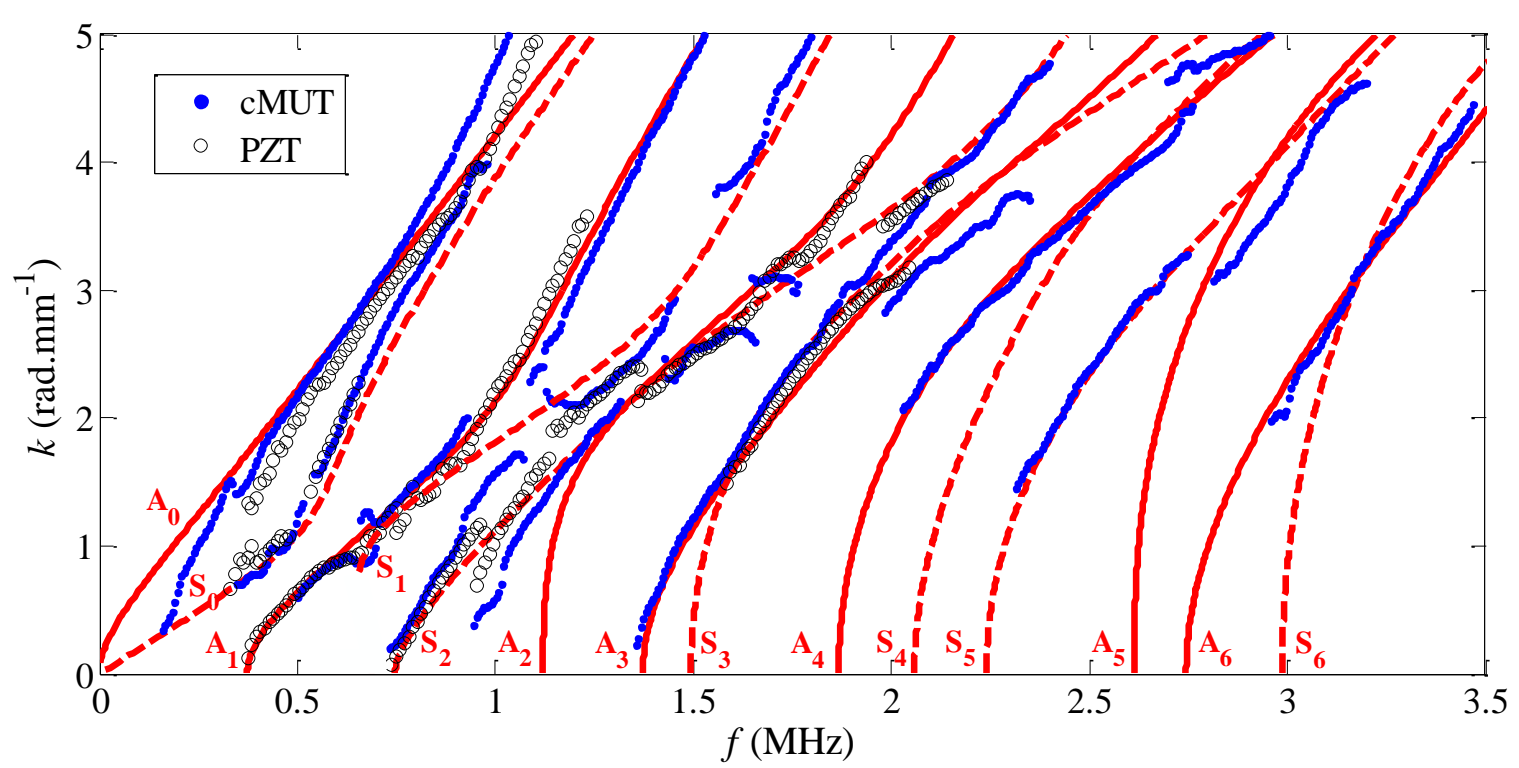

Fig. 15 Results for bone mimicking plate: dispersion curves calculated for the free solid plate (continuous and dashed lines) and experimental modes obtained with cMUT probe (blue dots) and PZT probe (black circles).

\section{CONCLUSION}

The aim of this work was to develop and test a cMUT-based linear array for evaluation of cortical bone with the axial transmission method. The main challenge was the fabrication of a probe able to generate low frequency ultrasound (100 kHz) as well as high frequency ultrasound (typically $2 \mathrm{MHz}$ ). To avoid onerous technological development, our strategy was to fabricate the probe with a standard microelectronic process already in use for medical imaging cMUT arrays for which the working frequency range is higher than $2.5 \mathrm{MHz}$. To shift the central frequency of cMUTs toward very low frequencies, the flexural rigidity of the diaphragm must be reduced, either by increasing lateral size, or by reducing thickness. However, the gap height needs to be significantly increased in order to compensate for the static deflection produced by the atmospheric pressure, meaning that a specific process had to be developed. We chose to design a linear probe, suited to the constraints of our surface micromachining process, with the lowest central frequency possible and using the quasistatic regime of cMUTs to generate low frequency ultrasound.

A complete probe comprising two groups of 5 emitters and 24 receivers was then fabricated and packaged, including specific low noise pre-amplification circuits in the head probe. Probe performance was evaluated at the 
level of each cell and then at the level of each element. Good homogeneity was demonstrated, despite the size of each element, and electroacoustic parameters were in agreement with those expected. Two major results were obtained with this first prototype. First, we demonstrated that cMUTs are able to emit and receive significant and usable acoustic pressure fields at very low frequencies, i.e. close to a quasistatic regime. Secondly, the bandwidth of the recorded signals was in the usable frequency range $(100 \mathrm{kHz}-2 \mathrm{MHz})$, with good sensitivity despite the strong attenuation of the bone medium. Finally, comparison with the PZT probe clearly demonstrated two major advantages of this technology for the determination of guided modes in the cortical bone: i.e. higher directivity pattern and higher frequency bandwidth. Moreover, despite the presence of preamplifying circuits, the overall dimensions of the probe were compatible with medical applications.

The next stage of this work is already in progress, i.e. the final integration of this probe prototype and its connection to a home-made beamformer dedicated to axial transmission measurement in order to implement a clinical evaluation. Finally, a new opportunity is being studied to exploit the effectiveness of this prototype in brain exploration which requires probes with similar properties allowing ultrasound to cross the bone barrier.

\section{ACKNOWLEDGMENTS}

We thank the Agence National de la Recherche and the Fonds Européen de Développement Régional for their financial support (COSTUM ANR-09-TECS-005-01 and FEDER COSTUM II 2657-33868).

\section{REFERENCES}

[1] C. E. Webber, "Photon absorptiometry, bone densitometry and the challenge of osteoporosis," Phys. Med. Biol., vol. 51, pp. R169-R185, Jul 2006.

[2] P. Laugier, "Instrumentation for in vivo ultrasonic characterization of bone strength," IEEE Trans. Ultrason. Ferroelectr. Freq. Control, vol. 55, pp. 1179-1196, Jun 2008.

[3] P. H. F. Nicholson, P. Moilanen, T. Karkkainen, J. Timonen, and S. L. Cheng, "Guided ultrasonic waves in long bones: modelling, experiment and in vivo application," Physiological Measurement, vol. 23, pp. 755-768, Nov 2002.

[4] P. Moilanen, P. H. F. Nicholson, V. Kilappa, S. Cheng, and J. Timonen, "Measuring guided waves in long bones: Modeling and experiments in free and immersed plates," Ultrasound Med. Biol., vol. 32, pp. 709-719, May 2006.

[5] A. Tatarinov, N. Sarvazyan, and A. Sarvazyan, "Use of multiple acoustic wave modes for assessment of long bones: Model study," Ultrasonics, vol. 43, pp. 672-680, Aug 2005.

[6] V. C. Protopappas, D. I. Fotiadis, and K. N. Malizos, "Guided ultrasound wave propagation in intact and healing long bones," Ultrasound Med. Biol., vol. 32, pp. 693-708, May 2006.

[7] D. A. Ta, K. Huang, W. Q. Wang, Y. Y. Wang, and L. H. Le, "Identification and analysis of multimode guided waves in tibia cortical bone," Ultrasonics, vol. 44, pp. E279-E284, Dec 2006.

[8] D. Hans, S. K. Srivastav, C. Singal, R. Barkmann, C. F. Njeh, E. Kantorovich, C. C. Gluer, and H. K. Genant, "Does combining the results from multiple bone sites measured by a new quantitative 
ultrasound device improve discrimination of hip fracture?," Journal of Bone and Mineral Research, vol. 14, pp. 644-651, Apr 1999.

[9] H. Sievanen, S. Cheng, S. Ollikainen, and K. Uusi-Rasi, "Ultrasound velocity and cortical bone characteristics in vivo," Osteoporos. Int., vol. 12, pp. 399-405, 2001.

[10] S. Prevrhal, T. Fuerst, B. Fan, C. Njeh, D. Hans, M. Uffmann, S. Srivastav, and H. K. Genant, "Quantitative ultrasound of the tibia depends on both cortical density and thickness," Osteoporos. Int., vol. 12, pp. 28-34, 20012001.

[11] P. Moilanen, P. H. F. Nicholson, T. Karkkainen, Q. Wang, J. Timonen, and S. Cheng, "Assessment of the tibia using ultrasonic guided waves in pubertal girls," Osteoporos. Int., vol. 14, pp. 1020-1027, Dec 2003.

[12] A. Tatarinov, A. Sarvazyan, G. Beller, and D. Felsenberg, "Comparative examination of human proximal tibiae in vitro by ultrasonic guided waves and PQCT," Ultrasound Med. Biol., vol. 37, pp. 1791-1801, Nov 2011.

[13] E. Bossy, M. Talmant, M. Defontaine, F. Patat, and P. Laugier, "Bidirectional axial transmission can improve accuracy and precision of ultrasonic velocity measurement in cortical bone: A validation on test materials," IEEE Trans. Ultrason. Ferroelectr. Freq. Control, vol. 51, pp. 71-79, Jan 2004.

[14] J. G. Minonzio, J. Foiret, M. Talmant, and P. Laugier, "Impact of attenuation on guided mode wavenumber measurement in axial transmission on bone mimicking plates," J. Acous. Soc. Am., vol. 130, pp. 3574-3582, Dec 2011.

[15] M. Muller, P. Moilanen, E. Bossy, P. Nicholson, V. Kilappa, T. Timonen, M. Talmant, S. Cheng, and P. Laugier, "Comparison of three ultrasonic axial transmission methods for bone assessment," Ultrasound Med. Biol., vol. 31, pp. 633-642, May 2005.

[16] M. Talmant, S. Kolta, C. Roux, D. Haguenauer, I. Vedel, B. Cassou, E. Bossy, and P. Laugier, "In vivo performance evaluation of bi-directional ultrasonic axial transmission for cortical bone assessment," Ultrasound Med. Biol., vol. 35, pp. 912-919, Jun 2009.

[17] F. Lefebvre, Y. Deblock, P. Campistron, D. Ahite, and J. J. Fabre, "Development of a new ultrasonic technique for bone and biomaterials in vitro characterization," Journal of Biomedical Materials Research, vol. 63, pp. 441-446, Aug 2002.

[18] J. Foiret, Q. Grimal, M. Talmant, R. Longo, and P. Laugier, "Probing heterogeneity of cortical bone with ultrasound axial transmission," IEEE Trans. Ultrason. Ferroelectr. Freq. Control, vol. 60, pp. 187193, 2013.

[19] P. Moilanen, "Ultrasonic guided waves in bone," IEEE Trans. Ultrason. Ferroelectr. Freq. Control, vol. 55, pp. 1277-1286, June 2008.

[20] J. Foiret, J. G. Minonzio, M. Talmant, P. Laugier, and Ieee, "Cortical bone quality assessment using quantitative ultrasound on long bones," in 2012 Annual International Conference of the Ieee Engineering in Medicine and Biology Society, ed New York: Ieee, 2012, pp. 1121-1124.

[21] S. D. Senturia, Microsystem Design: Kluwer Academinc, 2001.

[22] I. Ladabaum, J. Xuecheng, H. T. Soh, A. Atalar, and B. t. Khuri-Yakub, "Surface micromachined capacitive ultrasonic transducers," IEEE Trans. Ultrason. Ferroelectr. Freq. Control., vol. 45, pp. 678690, 1998.

[23] P. C. Eccardt, K. Niederer, T. Scheiter, and C. Hierold, "Surface micromachined ultrasound transducers in CMOS technology," in Proc. IEEE Ultrasonics Symposium, 1996, pp. 959-962 vol.2.

[24] O. Oralkan, A. S. Ergun, J. A. Johnson, M. Karaman, U. Demirci, K. Kaviani, T. H. Lee, and B. T. Khuri-Yakub, "Capacitive micromachined ultrasonic transducers: Next-generation arrays for acoustic imaging?," IEEE Trans. Ultrason. Ferroelectr. Freq. Control, vol. 49, pp. 1596-1610, Nov 2002.

[25] R. O. Guldiken, M. Balantekin, J. Zahorian, and F. L. Degertekin, "Characterization of dual-electrode CMUTs: Demonstration of improved receive performance and pulse echo operation with dynamic membrane shaping," IEEE Trans. Ultrason. Ferroelectr. Freq. Control, vol. 55, pp. 2336-2344, Oct 2008.

[26] G. Gurun, P. Hasler, and F. L. Degertekin, "Front-end receiver electronics for high-frequency monolithic CMUT-on-CMOS imaging arrays," IEEE Trans. Ultrason. Ferroelectr. Freq. Control, vol. 58, pp. 1658-1668, 2011.

[27] A. S. Savoia, G. Caliano, and M. Pappalardo, "A CMUT probe for medical ultrasonography: from microfabrication to system integration," IEEE Trans. Ultrason. Ferroelectr. Freq. Control, vol. 59, pp. 1127-1138, June 2012.

[28] M. Legros, C. Meynier, R. Dufait, G. Ferin, and F. Tranquart, "Piezocomposite and CMUT arrays assessment through in vitro imaging performances," in Proc. IEEE Ultrasonics Symposium, 2008, pp. $1142-1145$. 
[29] A. Novell, M. Legros, N. Felix, and A. Bouakaz, "Exploitation of Capacitive Micromachined Transducers for Nonlinear Ultrasound Imaging," IEEE Trans. Ultrason. Ferroelectr. Freq. Control, vol. 56, pp. 2733-2743, Dec 2009.

[30] S. H. Wong, R. D. Watkins, M. Kupnik, K. B. Pauly, and B. T. Khuri-Yakub, "Feasibility of MRtemperature mapping of ultrasonic heating from a CMUT," IEEE Trans. Ultrason. Ferroelectr. Freq. Control, vol. 55, pp. 811-818, 2008.

[31] N. Senegond, F. Teston, D. Royer, C. Meynier, and D. Certon, "High Voltage Time Domain Response of cMUT Membrane: Laser Interferometry Measurements," in Proceedings of International Congress on Ultrasonics 2009, pp. 1011-1016.

[32] A. S. Erguri, H. Yongli, Z. Xuefeng, O. Oralkan, G. G. Yarahoglu, and B. T. Khuri-Yakub, "Capacitive micromachined ultrasonic transducers: fabrication technology," IEEE Trans. Ultrason. Ferroelectr. Freq. Control, vol. 52, pp. 2242-2258, 2005.

[33] E. Jeanne, "Fabrication and characterization of capacitive micromachined ultrasonic transducer," Ph.D. Thesis, François Rableais university, Tours, 2008.

[34] C. Meynier, F. Teston, and D. Certon, "A multiscale model for array of capacitive micromachined ultrasonic transducers," J. Acous. Soc. Am., vol. 128, pp. 2549-2561, Nov 2010.

[35] P. Chatain, D. Voisin, M. Legros, G. Ferin, and R. Dufait, "Improving ultrasound imaging with integrated electronics," in Proc. IEEE Ultrasonics Symposium, 2009, pp. 2718-2721.

[36] N. Senegond, D. Certon, J. E. Bernard, and F. Teston, "Characterization of cMUT by Dynamic Holography Microscopy," in Proc. IEEE Ultrasonics Symposium, 2009, pp. 2205-2208.

[37] D. Certon, G. Ferin, O. B. Matar, J. Guyonvarch, J. P. Remenieras, and F. Patat, "Influence of acoustooptic interactions on the determination of the diffracted field by an array obtained from displacement measurements," Ultrasonics, vol. 42, pp. 465-471, Apr 2004.

[38] D. Certon, J. Guyonvarch, G. Ferin, and F. Patat, "Two-dimensional electroacoustic model of transducer array based on 1-3 piezocomposite materials," IEEE Trans. Ultrason. Ferroelectr. Freq. Control, vol. 53, pp. 2471-2480, 2006.

[39] J. A. Chen, J. Foiret, J. G. Minonzio, M. Talmant, Z. Q. Su, L. Cheng, and P. Laugier, "Measurement of guided mode wavenumbers in soft tissue-bone mimicking phantoms using ultrasonic axial transmission," Phys. Med. Biol., vol. 57, pp. 3025-3037, May 2012.

[40] B. Bayram, M. Kupnik, C. G. Yaralioglu, O. Oralkan, A. S. Ergun, D. S. Lin, S. H. Wong, and B. T. Khuri-Yakub, "Finite element modeling and experimental characterization of crosstalk in 1-D CMUT arrays," IEEE Trans. Ultrason. Ferroelectr. Freq. Control, vol. 54, pp. 418-430, Feb 2007.

[41] J. McLean and F. L. Degertekin, "Directional scholte wave generation and detection using interdigital capacitive micromachined ultrasonic transducers," IEEE Trans. Ultrason. Ferroelectr. Freq. Control., vol. 51, pp. 756-764, Jun 2004.

[42] C. L. Yapura and V. K. Kinra, "Guided-waves in a fluid solid bilayer," Wave Motion, vol. 21, pp. 3546, Feb 1995. 